\author{
SERIES "CONTRIBUTIONS FROM THE EUROPEAN RESPIRATORY MONOGRAPHS" \\ Edited by M. Decramer and A. Rossi \\ Number 2 in this Series
}

\title{
Epidemiology of chronic obstructive pulmonary disease
}

\author{
J.M. Antó*,\#, P. Vermeire ${ }^{\varpi}$, J. Vestbo ${ }^{+}$, J. Sunyer*
}

\begin{abstract}
Epidemiology of chronic obstructive pulmonary disease. J.M. Antó, P. Vermeire, J. Vestbo, J. Sunyer. C) ERS Journals Ltd 2001.

ABSTRACT: Chronic obstructive pulmonary disease (COPD) is a leading cause of world-wide mortality and disability. On average $\sim 5-15 \%$ of adults in industrialized countries have COPD defined by spirometry. In 1990, COPD was considered to be at the twelfth position world-wide as a cause of combined mortality and disability but is expected to become the fifth cause by the year 2020 .

COPD has a chronic long-lasting course characterized by irreversible decline of forced expiratory volume in one second (FEV1), increasing presence of dyspnoea and other respiratory symptoms, and progressive deterioration of health status. After diagnosis the 10 -yr survival rate is $\sim \mathbf{5 0} \%$ with more than one-third of patients dying due to respiratory insufficiency.

Several environmental exposures such as air pollution increase the risk of death in COPD patients. The aetiology of COPD is overwhelmingly dominated by smoking although many other factors could play a role. Particular genetic variants are likely to increase the susceptibility to environmental factors although little is known about which are the relevant genes. There is clear evidence about the role of the $\alpha$-1-antitrypsin but the fraction of COPD attributable to the relevant variants is only $1 \%$. Phenotypic traits that are considered to play a role in the development of COPD include sex, with females being at a higher risk, bronchial responsiveness and atopy. There is strong causal evidence regarding the relationship between smoking and COPD with decline in FEV1 levelling off after smoking cessation. Passive smoking has been found to be associated with a small though statistically significant decline in FEV1. Other risk factors that are likely to be relevant in the development of COPD are occupation, low socioeconomic status, diet and possibly some environmental exposures in early life.

Although there is accumulating evidence that oxygen therapy, pharmacological treatment and rehabilitation may improve the course of chronic obstructive pulmonary disease, preventing smoking continues to be the most relevant measure, not only to prevent chronic obstructive pulmonary disease, but also to arrest its development. Eur Respir J 2001; 17: 982-994.
\end{abstract}

\begin{abstract}
* Respiratory and Environmental Health Research Unit, Institut Municipal d'Investigació Mèdica (IMIM), Barcelona, Spain, ${ }^{\#}$ Dept of Experimental and Health Sciences, Universitat Pompeu Fabra (UPF), Barcelona, Spain, Dept of Pulmonary Medicine, University of Antwerp (UIA), Antwerp-Wilrijk, Belgium and ${ }^{+}$Dept of Respiratory Medicine, Hvidovre University Hospital, Denmark.
\end{abstract}

Correspondence: J.M. Antó, Respiratory and Environmental Health Research Unit, Institut Municipal d'Investigació Mèdica (IMIM), Carrer del Doctor Aiguader, 80, E-08003Barcelona, Spain.

Fax: 34932213237

Keywords: $\alpha$-1-antitrypsin deficiency chronic obstructive pulmonary disease epidemiology

passive smoking

smoking

Received: February 82001

Accepted after revision February 22 2001
Chronic obstructive pulmonary disease (COPD) is a leading cause of mortality and morbidity both in developed and developing countries that is mainly characterized by progressive and not fully reversible airflow limitation. As an important health problem it has been the subject of many epidemiological and clinico-epidemiological investigations that have addressed a broad range of issues from aetiology to health services utilization. In the following sections a comprehensive narrative review of the epidemiological knowledge about COPD that has accumulated during the recent decades is provided.

\section{Definition of chronic obstuctive pulmonary disease}

The 1995 European Respiratory Society (ERS) consensus statement [1] defined COPD as "a disorder characterized by reduced maximum expiratory flow and slow emptying of the lungs; features which do not change markedly over several months. Most of the airflow limitation is slowly progressive and irreversible. The airflow limitation is due to varying combinations of airways disease and emphysema; the relative contribution of the two processes is difficult to define in vivo". Unfortunately, there is no agreed labelling of the airways disease component that is mainly an inflammatory process. Labelling the airways disease component as obstructive bonchiolitis [2, 3] has some advantages but has not found general acceptance. In the 1995 American Thoracic Society (ATS) Statement COPD was defined as a "disease state characterized by presence of airflow obstruction due to chronic bronchitis or emphysema; the airflow obstruction is generally progressive, may be accompanied by airways hyperreactivity and may be partially reversible" [2]. However, 
the use of the term chronic bronchitis in the definition of COPD may easily generate confusion since it is widely used to designate mucus hypersecretion that originates mostly from larger airways.

In order to make the definition operative the ERS consensus defined COPD as an airflow obstruction with a forced expiratory volume in one second (FEV)1/ forced vital capacity (FVC)L 88\% predicted in males or $<89 \%$ pred in females [1]. In this definition the following entities are excluded from COPD: cystic fibrosis, bronchiectases, byssinosis and bronchiolitis obliterans. However, when both positive and negative criteria are applied to a case definition the distinction between asthma and COPD is still a major difficulty. Obviously, the adoption of different definitions or the translation of the same definition to different operational criteria may lead to different estimations of either prevalence rates or risks and consequently make more difficult the interpretation of apparently inconsistent results. A consequence of the ambiguity underlying the definition of COPD is that of smoking. Although the antecedent of smoking is not included in any of the definitions of COPD alluded to above, many clinical investigations do exclude nonsmokers.

\section{Frequency, distribution and trends}

In the USA, a history of emphysema diagnosed by a physician or a measured level of impaired lung function (usually FEV $1<60$ or $65 \%$ of its predicted value) was found in $4-6 \%$ of adult White males and $1-3 \%$ of adult White females [4]. In Black populations, prevalence of COPD (FEV1 $<65 \%$ pred) was $3.7 \%$ in males and $6.7 \%$ in females, in 1971-1975 [5]. In a review about the prevalence in the UK, STRACHAN [6] mentioned the Health and Life Style Survey as the only national study of ventilatory function among a British adult population [7]. This survey included 2,484 males and 3,063 females aged 18-65 yrs, in whom a spirometry was performed at home. Overall, $10 \%$ of males and $11 \%$ of females showed an FEV1 of two or more standard deviations below the age and height predicted value. The prevalence of obstruction increased by age. In the IBERPOC study, carried out in a sample of the 40-69 yr old population in Spain, an FEV1/FVC ratio $<88 \%$ pred in males and $<89 \%$ in females with a negative bronchodilator test was found in $15.8 \%$ of males and in 5.5\% of females [8]. Prevalence rates of chronic bronchitis were similar in several European countries with rates of $3.7 \%$ in Denmark [9], $4.5 \%$ in Norway [10], 4.8\% in Spain [8]. One of the major differences between epidemiology and clinical pulmonary medicine relates to mild COPD. For the clinician mild COPD is rarely seen and the term "COPD" often relates to severe disease. However, from an epidemiological perspective it is important to understand that a prevalence rate includes the entire spectrum of severity and that the majority of cases will have a mild COPD. This important distinction is well illustrated by an analysis of clinically small effects of air pollution on FVC [11]. This study shows that, in an evidence-based scenario of air pollution, a $3.14 \%$ shift in the population mean FVC may have a rather strong impact on the prevalence of people with severely impaired FVC, although the same decrement at individual level would have no clinically relevance.

Since the duration of COPD usually involves several decades, prevalence rates poorly reflect time trends. STRACHAN [6] has reviewed data from three National Morbidity Surveys in General Practice, showing that the number of both males and females aged 65-74 yrs consulting a general practitioner for emphysema and COPD increased from $11.1 \%$ and $1.5 \%$ in $1970-1971$ to $26.2 \%$ and $7.8 \%$ in $1980-1981$. However, interpretation of this type of data is seriously limited, not only because of factors related to diagnostic shift and changes in services utilization but also because it is largely dependent on prevalence rather than on incidence rates.

Another source of information about time and geographical patterns is mortality. Unfortunately, in addition to the limitations in the validity of medical diagnoses in death certificates, the analysis of COPD mortality is further complicated by the lack of a wellstandardized three-digit code for COPD. In a review of international patterns of respiratory mortality entities with the ICD9 490-496 codes which also include asthma (ICD9 493), the highest rates were found in UK, Eastern Europe and Australia and the lowest rates in Southern Europe, Scandinavian countries, Israel and Japan [12]. In the ERS Consensus Statement, after considering together the ICD codes 490-493, the mortality rates in males for the period 1988-1991 ranged from $>30$ deaths per 100,000 person-yrs in Hungary, Denmark and former East Germany to $<10$ in Spain, France and Greece [1]. One of the limitations of mortality studies is related to the use of the underlying cause of death as the only information to establish the cause of death. MANNINO et al. [13] used the Multiple-Cause Mortality Files compiled by the National Centre for Health Statistics in the US and found that $8.2 \%$ of all deaths had a diagnosis of obstructive lung disease (ICD-9 490-493.9, 496). COPD was recorded as the underlying cause of death in $43 \%$ of all these deaths, showing that mortality due to COPD may be severely underestimated when using only the underlying cause of death.

Studies about the trends in mortality due to COPD are useful in order to assess changing needs and to anticipate knowledge about expanding problems. This is of particular interest for COPD mortality in females. In Australia, female age-standardized mortality increased by 2.6-fold from 1964-1990 and it was predicted that female mortality by COPD may equal mortality in males by the middle of the next decade [14]. A similar pattern was shown in a study of the US national trends in mortality by obstructive lung disease from 1974-1993 with the age-adjusted rates for females increasing by $126 \%$ [13]. World-wide distribution of disability-adjusted life's year (DALYS) due to COPD has been assessed within the frame of the Global Burden Disease Study [15]. The DALYS result from the sum of life's years lost due to premature death and the years lived with disability. COPD was responsible for $2.1 \%$ of DALYS and, among the most common causes, ranked twelfth in 1990 . When current trends were projected according to several scenarios, COPD 
was estimated to be the fifth cause of DALYS in the year 2020 accounting for $4.1 \%$ of DALYS appearing as one of the most important increasing public health problems world-wide

\section{Course and progression of chronic obstructive pulmonary disease}

In general, a first diagnosis of COPD is established in subjects $>40-50$ yrs who have been smokers for several decades. However, before reaching this clinical stage a long course of structural and functional changes in the lungs has occurred. This course includes relevant changes and events involving deterioration of lung function, appearance of symptoms, worsening of health-related quality of life, active use of health services and frequently, death due to COPD.

\section{Decline in forced expiratory volume in one second}

The natural history of COPD is mainly characterized by a progressive, irreversible, decline in lung function. In healthy subjects lung function achieves its maximum value at the age of $20-25$, followed by a slow progressive decline with age. In a study of 792 healthy males, 30-59-yr-olds followed for up to 8 yrs [16], the decline of FEV1 in nonsmokers was $\sim 25 \mathrm{~mL} \cdot \mathrm{yr}^{-1}$ in contrast to $50 \mathrm{~mL} \cdot \mathrm{yr}^{-1}$ in smokers. Those with the sharpest decline had a slope of FEV1 decline about $100 \mathrm{~mL} \cdot \mathrm{yr}^{-1}$ and then developed respiratory symptoms and severe obstruction. A later study by BuRRows et al. [17] did show that the decline in FEV1 was independent of its basal value. The decline of the FEV1 has been the subject of several reviews $[18,19]$. The results of the longitudinal studies have been summarized by RIJCKEN and BRITTON [19] showing FEV1 declines ranging from $7 \mathrm{~mL} \cdot \mathrm{yr}^{-1}$ in the six-city study to $33-\mathrm{mL} \cdot \mathrm{yr}^{-1}$ in the University of California Los Angeles (UCLA) population study. An important issue is that the earliest step of COPD may involve a suboptimal development of lung function during childhood and adolescence which in combination with a slightly accelerated decline at a later age may lead to significant airflow limitation [20].

\section{Symptoms and quality of life}

When and how symptoms appear during the silent evolution of FEV1 decline has been a contentious issue. Although most smokers do experience chronic cough and expectoration at an early age, its relationship with COPD is far from clear. FLETCHER et al. [16] observed that about one-quarter of smokers with a low FEV1 did not present chronic cough and expectoration whereas $20 \%$ of smokers with chronic productive cough showed a normal FEV1, and concluded that mucus hypersecretion and decreased FEV1 were different entities. This conclusion was supported by several subsequent studies that have shown either no, or small, association of mucus hypersecretion and the decline of FEV1 [21, 22]. These findings are consistent with the notion that the decline in FEV1 in COPD is due mainly to smoking with, at most, only a weak relationship with chronic bronchitis or mucus hypersecretion. Since mucus hypersecretion is frequently associated with lower respiratory tract infections, additional support to this notion was provided by trials of preventive antibiotic therapy in subjects with chronic bronchitis showing no influence on the rate of FEV1 decline [23]. As a consequence there is the extended belief that chronic cough and expectoration in absence of COPD is a minor disorder without a relevant impact in the health status. By contrast, ANNESI and KAUFFMAN [24] found in a longitudinal study that after adjustment for relevant covariates, working people with chronic mucus hypersecretion had an increase of $35 \%$ of the all-cause mortality. More recently, VestBo et al. [25] have found an association between mucus hypersecretion and a decline in both FEV1 and hospital admissions because of COPD. These studies do clearly question the idea that chronic cough and expectoration is a minor disorder although the reasons for this discrepancy have not yet been clarified.

Breathlessness is another important symptom in COPD. Fletcher and Peto [26] found that breathlessness was the symptom associated with the largest loss of lung function over time as well as to a worse prognosis. When breathlessness appears, as a consequence of loss of lung function, is not known with precision. In addition, the coexistence of decreased FEV1 and dyspnoea do show a wide interindividual variability [27].

Another relevant aspect in the course of COPD is health-related quality of life (HRQL). There are several cross-sectional studies showing that there is a relevant deterioration of quality of life in COPD [28]. Although it has been considered that a relevant impairment of quality of life only occurs in advanced COPD there are few studies conducted in milder stages. FERRER et al. [29] in a cross-sectional study of 321 COPD patients, showed that those with an FEV $1>49 \%$ pred had a substantial impairment of their quality of life (34 points in the Saint George Respiratory Questionnaire (SGRQ) total score as compared to 6 in the reference value). Also a substantial impairment was found for those who were not troubled with shortness of breath except with strenuous exercise [29]. Knowledge about the longitudinal decline in health status in patients with COPD has been gained in the inhaled steroids in obstructive lung disease (ISOLDE) study, a randomized placebo-controlled trial of inhaled corticosteroids, assessing the placebo group [30, 31]. OsmAN et al. [32] have shown that HRQL scores can predict re-admission for COPD. In a study of 266 patients admitted with an exacerbation of COPD, these authors showed that those with a worse score on the SGRQ had a higher rate of re-admission for COPD independently of FEV1. This type of longitudinal evidence reinforces the current understanding that quality of life is among the most important dimensions in the evolution of COPD.

\section{Acute exacerbations}

The exacerbation of COPD is considered the most common cause for hospital admission in COPD patients. Despite the fact that COPD patients may 
experience several exacerbations per year [33] the influence of acute exacerbations on the progression of COPD has not been established. SEEMungal et al. [34] have recently reported a longitudinal study of 70 COPD patients showing that those with more frequent exacerbation (3-8 during follow-up) had SGRQ scores significantly worse than those with less frequent exacerbation. Acute exacerbations, at least the most severe ones that require hospital admission, are associated with high risk of death with $\sim 10-30 \%$ of subjects dying during the admission and about $40-60 \%$ during the year following the admission $[35,36]$. It is of interest here that in the Copenhagen City Heart Study [25], as mentioned earlier, chronic mucus hypersecretion was also associated with an increased risk of hospital admissions because of COPD. Because the limited lung function in the advanced COPD is likely to be a risk factor for an acute exacerbation the causal path between infection induced exacerbations and progression of COPD may involve complex interactions between acute events across short time periods. This type of inter-relationship is further strengthened by another analyses from the Danish group showing that the relationship between chronic mucus hypersecretion and COPD mortality was entirely due to death from COPD when a terminal infection was present [37].

\section{Mortality}

After years of suffering dyspnoea and disability many patients with COPD die as a consequence of the disease. Mortality from COPD, however, is often underestimated due to misclassification and frequent comorbidity. In the study of FLETCHER et al. [16] the 10 -yr survival after a clinical diagnosis, in those who persisted in smoking, was $\sim 50 \%$ whereas in exsmokers it was $\sim 80 \%$, a pattern that correlates with decline in FEV1 according to smoking. Among cohorts in the Seven Countries Study, the relative risk of death from any cause in 15 yrs of follow-up, adjusted for several risk factors including age and smoking, was 1.67 (95\% confidence interval (CI):1.48-1.88) for those with COPD and it showed large variability between countries [38]. Other functional traits like bronchial responsiveness and reversibility have also been investigated in its relationship with prognosis of COPD. ANTHONISEN et al. [39] did follow-up a population of 985 patients with COPD for 3 yrs in Canada. As expected age and FEV1 were the strongest predictors of death. The same was found in a population study where COPD was not subject to any referral bias [40]. In the Canadian study, the response to the bronchodilator test was significantly related to death when the pre-bronchodilator FEV1 was included but the association became nonsignificant when post-bronchodilator FEV1 was used as primary predictor [39]. Another study found an opposite effect of bronchodilator response on survival [41]. The main understanding today seems to be that as prebronchodilator FEV1 is subject to large variability and postbronchodilator FEV1 is an excellent predictor of vital status, reversibility may falsely be interpreted as a marker of good prognosis [42].
In addition to FEV1 other lung and heart function parameters have been found associated to survival in COPD. Follow-up of a series of cases with well advanced COPD have shown that in addition to respiratory parameters like oxygen tension in arterial blood $\left(\mathrm{Pa}, \mathrm{O}_{2}\right)$, carbon dioxide tension in arterial blood $\left(P \mathrm{a}, \mathrm{CO}_{2}\right), \mathrm{FEV} 1, \mathrm{FVC}$ and cor pulmonale, other markers of the cardiovascular function like ventricular ejection fraction and ECG abnormalities are also associated to increased mortality [43-45]. Little is known about the specific causes of death in subjects with COPD. In a study of $\sim 200$ COPD patients, the most common causes of death were respiratory failure $(38 \%)$, cor pulmonale with oedema $(13 \%)$, pulmonary infections $(11 \%)$, and pulmonary embolism (10\%) [44] suggesting that progressive respiratory failure is only responsible for a proportion of deaths in COPD patients, and that other conditions also play a role. To which extent the previously described factors may be clinically useful to predict death after an admission for COPD is difficult to answer. In a prospective cohort of 1,016 adult patients admitted with an exacerbation of COPD and a $P \mathrm{a}_{1} \mathrm{CO}_{2}$ of $\geqslant 50 \mathrm{mmHg}$, the survival time was independently related to severity of illness, body mass index, age, prior functional status, $\mathrm{Pa}_{\mathrm{a}} \mathrm{O}_{2} /$ inspiratory oxygen fraction $\left(F \mathrm{I}, \mathrm{O}_{2}\right)$, congestive heart failure, serum albumin, and the presence of cor pulmonale [36]. A multivariate model based on these variables was used to predict the probability of death at 6 months, but the accuracy of the model was similar to the prognoses predicted by the responsible physicians [36]. A number of studies have considered whether mucus hypersecretion, that in severe COPD may promote infection, is associated with an increased risk of death. The results of several studies have been inconsistent with ones showing no or small association [46, 47] and others showing a moderate to strong association [48, 49]. The possibility that clinical heterogeneity in COPD could be associated to mortality had been suggested by Burrows et al. [3] who found that in a sample of general population with chronic airflow obstruction at recruitment those with asthmatic characteristics had a lower mortality than those with an emphysematous form of COPD.

Few studies have considered the existence of sexrelated survival differences in COPD and have shown that survival rates were lower in males compared to females. One of these studies included 2,237 patients aged 65-69 yrs with a first hospital admission due to COPD during the period 1986-1990 with mortality assessed until 1993 [50]. Overall mortality in this group at the end of the study period was $\sim 48 \%$ with a median survival time of 5.7 yrs with female COPD patients having a more favourable prognosis than males. In a study of 15,517 subjects visiting an emergency room service in Barcelona, Spain, with either asthma or COPD, fatality rates after a diagnosis of COPD were higher in males than in females. The higher fatality rates in males were seen for all-cause mortality, for all respiratory deaths, and for mortality due to COPD [51]. Whether the higher lethality in males as reported in these studies was due to differences in management or in severity requires further investigation. 
Environmental influences in the course of chronic destructive pulmonary disease

Modern evidence about the effects of air pollution on lung health started in the early fifties with thousands of deaths occurring during the fog episode in London 1952, the majority of whom involved subjects diagnosed of bronchitis [52]. Further studies conducted in panels of patients suffering from chronic bronchitis in UK [53] and USA [54] confirmed an association between air pollution and exacerbation of chronic bronchitis. These studies were very influential and clean air policies were developed in many industrialized countries and air pollution levels did show a generalized decrease. Subsequent studies conducted in areas with lower levels of air pollution did not observe an increase of respiratory symptoms or respiratory diseases associated with air pollution $[55,56]$. Although disputed there was a widespread belief that air pollution levels achieved through the establishment of environmental standards did protect health with a margin of safety. However, a new generation of time series studies was reported in the 1990s showing an increase in all-cause mortality and mortality from COPD in days with higher levels of particulate pollution $[57,58]$. Studies conducted in very different environments have consistently observed that admissions due to COPD increased on days with high pollution levels [59-65]. That these results were not due to site selection bias has been strongly supported by a recent study in the USA [66]. To which extent the increase in hospital admissions and mortality from COPD is due to a small anticipation of events, that nevertheless would have occurred some days later, has been a matter of debate. However, several recent studies have shown only a small if any impact of anticipation of effects [67].

\section{Aetiology}

\section{Genetic determinants}

Since only $10-20 \%$ of smokers develop COPD a strong role of genetic susceptibility seems reasonable. However, it is increasingly recognized that the genetic determinants of COPD are likely to be complex and have only recently started to receive attention. In a comprehensive recent review [68], the following candidate genes were seen as potentially responsible for COPD: $\alpha$-1-antitrypsine gene, $\alpha$-1-quimitrypsine genes, $\alpha$-2-macroglobuline genes, the vitamin D coupling protein and the blood-serotype group genes. However, there was only definite evidence for $\alpha$-1-antitrypsine (AAT). The AAT gene is highly polymorphic with $>75$ different alleles described some of them expressing low serum levels of AAT. The more common variants were the alleles $\mathrm{M}, \mathrm{S}$ and $\mathrm{Z}$ with population frequencies of about $0.93,0.05$ and 0.02 respectively. Almost all persons affected by a severe AAT deficiency are homozygous for the $\mathrm{Z}$ allele. However, because the low prevalence of the relevant AAT variants, the proportion of COPD attributable to this gene was only $\sim 1 \%$. A few studies assessing the association between different genotypes and the development of COPD suggested that those with an MZ genotype could be at higher risk of COPD than those with an MM genotype $[69,70]$. Other recent findings include studies showing an association between the presence of deoxyribonucleic acid (DNA) instability and COPD in smokers [71] and a higher frequency of the glutathione S-transferase (GSTP1) polymorphism in patients with COPD [72]. As with many other chronic diseases the hope is that after identification of the relevant genetic determinants of COPD the analysis of gene-environment interactions may allow for a more complete identification of environmental risk factors.

Phenotypic susceptibility: sex, bronchial hyperresponsiveness and atopy

Several studies have suggested that females may be at higher risk of developing COPD, although none of these studies have totally controlled for circumstances of exposure. The underlying physiological mechanisms for the females to be at an increased risk have been considered to involve either hormonal homeostasis or structural development of lungs. Recent evidence that adolescent females exposed to smoking may have a higher risk of reaching a lower maximally attained lung function than nonsmokers compared to males has been provided by GoLD et al. [73]. However, the interpretation of the studies in this age group is limited by the different age-pattern of lung function development in both sexes [74]. In addition, most biases in this field will tend to underestimate the effects of smoking in females, as males not only smoke more than females, they often have started earlier and have a higher rate of inhalation than females [75]. Further evidence in support that females are at a higher risk of COPD due to smoking has been recently provided by the analysis of two population-based cohorts in Denmark. Overall, 13,897 subjects born after 1920 were followed up for 7-16 yrs. In both cohorts, risk of hospital admission due to COPD associated with pack-years was higher in females than in males [76]. Similar results have been reported by SILVERMAN et al. [77] in a study on firstdegree relatives of patients with severe, early onset COPD showing that both current and exsmoking females had a significantly greater decrease of FEV1 than males. The finding reported by PAOLETTI et al. [78] that females have a higher rate of bronchial hyperresponsiveness after adjusting for baseline lung function, may provide a mechanism to explain the higher risk of females' FEV1 decline.

The role of bronchial responsiveness and atopy as possible effect modifiers of COPD risk has been reviewed in close detail in two reviews $[19,79]$ showing that subjects who are hyperresponsive have lower lung function either at a given time or over a period of time with a difference between both groups that in some studies was large. Whereas some authors have considered that bronchial hyperresponsiveness does predispose to loss of lung function, others have considered that bronchial responsiveness may be a result of smoking induced airways inflammation instead of a direct cause of lung damage. In a 24-yr follow-up of 
2,684 people from Vlagtwedde and Vlaardingen in Netherlands [80], it was shown that the odds for bronchial responsiveness among incident cases of chronic cough and chronic phlegm, after adjusting for age, sex, area, and smoking, were about two-fold the corresponding odds in those who persisted without these symptoms until the end of the follow-up. Similarly, those with bronchial responsiveness were at a lower risk of remission of these symptoms, after excluding subjects with asthma from the analysis. That these findings are relevant for COPD is supported by a further analysis in the same study showing that mortality from COPD increased with increasing bronchial hyperresponsiveness [81].

Asthma in itself should in general be regarded as a disease entity separate from COPD. It may thus seem confusing to add asthma to the risk factors for COPD. There is, however, increasing evidence from wellconducted population surveys that asthmatics have a more rapid decline in FEV1 than nonasthmatics [82, 83] and the excess decline is not trivial. In the Southern California cohort study a history of asthma was associated with a deficit in the maximum mid expiratory flow that was larger in male children than in female, although the influence of duration of asthma could not be excluded [84]. In addition, asthma in The Copenhagen Heart Study was associated with an increased mortality, primarily due to an increased COPD mortality [85]. The mechanism behind these observations are likely to be airways remodelling and a fixed airflow obstruction fulfilling all the definitions of COPD secondary to asthma not properly controlled for.

\section{Active and passive smoking}

Beyond any reasonable doubt the most important causal factor of COPD is active smoking even though only a proportion of the heavy smokers will develop the disease. Following the natural history of COPD, the first question is to what extent smoking is a cause of fixed airways obstruction and loss of function. The available evidence consistently shows that smokers are at a higher risk of decreased FEV1 both in crosssectional and longitudinal studies with an FEV1 decline ranging from $7 \mathrm{~mL} \cdot \mathrm{yr}^{-1}$ [86] to $33 \mathrm{~mL} \cdot \mathrm{yr}$ [87]. There is also consistent evidence about a dose-response relationship between the amount of smoking and the decline in FEV1. Regarding the reversion of COPD after smoking cessation, the available evidence [88] is consistent with the results of the seminal study by Fletcher et al. [16] who showed that after smoking cessation the FEV1 decline levels off without returning to the basal level.

A more contentious issue has been the assessment of the relationship between passive exposure to smoking and risk for COPD, although its understanding has been facilitated by a recent systematic review on this topic [89]. In this review it was concluded that maternal smoking is associated with small but statistically significant deficits in FEV1 and other spirometric indices in school-aged children and that this association was almost certainly causal [89]. One of the largest studies included in this review was the Six Cities Study
[73] which showed that the association between exposure to environmental tobacco smoke and FEV1 although significant, was of a small magnitude $\left(-3.8 \mathrm{~mL} \cdot \mathrm{yr}^{-1}\right)$.

\section{Air pollution}

The evidence about a relationship between outdoor air pollution and the development of COPD is still incomplete since most of the studies have focused on lung function, chronic bronchitis and mortality rather than on clinical definitions of COPD. Regarding lung function, there is abundant data from both studies in adults and in children. Evidence that adults living in areas with higher levels of air pollution have lower levels of lung function has been obtained in studies on British postmen during the 1960s [90], general population in Holland [91] and young adults in Southern California (The UCLA-Chronic Obstructive Respiratory Disease (CORD) study) [92, 87]. In the UCLA-CORD study no differences in FEV1 by area were observed in females who smoked. More recently the SAPALDIA study in Switzerland also found that levels of particulate matter $<10 \mu \mathrm{m}$ (PM10) and home outdoor measurements of $\mathrm{NO}_{2}$ [93] as well as personal measurements of $\mathrm{NO}_{2}$ [94] were related with a lower FVC. In the ASHMOG cohort of nonsmoking subjects in California, the assigned personal air pollution to PM10, based on distance of the residence from 348 monitoring stations, was associated with lower levels of FEV1 [95]. Similar findings have been obtained for children although in this case the process of growth complicates the analysis of changes in lung function. An association between increased levels of particulate air pollution and a decreased lung function growth has been reported in cross-sectional studies in the USA and Canada [96-98]. On the other hand, cohort studies in Poland [99] and Southern California [100] have shown that both particles and $\mathrm{NO}_{2}$ were related to lower levels of lung function. In addition, in a further cohort study in children from Austria and Germany ozone levels were associated with decreased lung function growth [101].

The assessment of the association between air pollution and clinical phenotypes related to COPD has included chronic bronchitis and mortality. During the 1950s, researchers in the UK had shown that prevalence of chronic bronchitis and cor pulmonale appeared to be greater in postmen from areas with higher pollution than in postmen from other areas [102], which was confirmed in a later study on the general population [103]. A higher prevalence of respiratory diseases compatible with COPD in areas with higher air pollution was also observed in the USA [104-106] and Poland [107]. The AHSMOG study [108] and SAPALDIA study [109] consistently found a higher prevalence of symptoms of hypersecretion, breathlessness, or diagnoses of chronic bronchitis, emphysema or COPD in areas with higher particulate air pollution. There have been three prospective cohort studies in the USA [110-113] on the relationship between residential exposure to air pollution and mortality in the general population. Two of the studies reported an increase in mortality for cardiopulmonary 
conditions $[110,111]$ and a third for nonmalignant respiratory diseases in areas with higher levels of air pollution $[112,113]$.

It is difficult to conclude from these studies that a certain pollutant is related with the slowing of the lung function development, due to the poor characterization of the atmosphere components and the problem of comparing between few levels of exposure (i.e. high and low exposures). However, the prospective nature of some studies, and the inclusion of the main covariates, suggests that urban air pollution may be involved in lung function development and consequently be a risk factor of COPD.

\section{Occupation}

In a recent review, HENDRICK [114] concluded that some occupational environments are likely to involve a risk of COPD, that this effect, although variable, is likely to be less potent than the smoking effect and that interactions between smoking and occupations are probably relevant. In industry-based studies, several exposures in particular occupations have been considered a risk for COPD including: grain, isocyanates, cadmium, coal and other mineral dust and welding fumes. Population-based studies have the advantage of providing a comprehensive view of the relationship between occupation and COPD. In the frame of the European Community Respiratory Health Society (ECRHS) study in young general population, exposure to high levels of biological dust, measured with a job exposure matrix, was associated with lower levels of FEV1 in Spain [51]. However, this association was only of a significant magnitude in some of the participating countries in the ECRHS, but not in the overall population. In a longitudinal population-based study in Zutphen, Holland, the occupations that were found to be at higher risk of nonspecific chronic lung disease were: wood and paper workers, tailors, construction and transport workers; among the exposures the ones with an increased risk included heavy metals, mineral dust and adhesives [115]. In this study almost $40 \%$ of males were occupationally exposed and had a risk ratio of 1.46 [116], suggesting that although the occupational risk is small it affects a large proportion of the population and their contribution to the ultimate incidence of COPD may not be negligible. By contrast, in population-based studies it may be difficult to assess a complete life-exposure. The Zutphen study showed that the use of a complete occupational history leads to a stronger association between occupation and chronic obstructive lung disease as compared to analysis considering occupation since the start of the follow-up [116]. The important different types of bias in the occupational studies on COPD were illustrated in a review of studies in gold and coal miners performed by OxMAn et al. [117]. Following a well-defined methodology for systematic reviews, encompassing more than 2,500 citations, 74 articles met the initial criteria and only 13 used quantitative measurement of dust exposure and controlled for both smoking and age. The authors concluded that biases were likely to result in a substantial underestimation of $\sim 50 \%$ of the true effects [118].

\section{Nutrition}

In the last years the potential protective role of some nutrients in the development of COPD has received increasing attention. Because of the wide availability of some of these dietary components, their potential role in the prevention of COPD is a relevant issue. Most of the evidence refers to vitamins $\mathrm{C}$ and $\mathrm{E}$, which have an antioxidant action which may supposedly counteract the oxidative damage produced by exposures like smoking and air pollution. Subjects with a low intake of fresh fruits had an FEV1 on average $80 \mathrm{~mL}$ lower than expected in a study conducted in the UK [119], with a similar finding being reported in the NHANES I population in the USA [120]. Regarding other nutrients, BRITTON et al. [121] have reported an association between FEV1 and magnesium intake independent of the association with vitamin $\mathrm{C}$. It has also been reported that a relatively high intake of $\omega-3$ fatty acids, which are inhibitors of the arachidonic acid metabolism, may protect against the development of COPD [122] in smokers. This latter type of protective effect is consistent with the Zutphen Study [123]. In a recent analysis of the smokers in the NHANES I population adults reporting a high fish consumption had a higher FEV1 than those with low fish consumption [124]. Several human intervention studies have been conducted showing inconsistent associations between supplements of eicosapentaenois acid and respiratory outcomes suggesting a possible difference between long-term and short-term effects [124].

\section{Socioeconomic status}

In a recent review, a consistent association between socioeconomic status and COPD was reported [125]. These studies included a variety of COPD related entities. Some of the studies have focused on respiratory symptoms and lung function. Regarding lung function, these studies have reported significant adjusted associations between low socioeconomic status and lower FEV1 and or FVC, with a difference in FEV1 between the extreme groups of socioeconomic status of $200-400 \mathrm{~mL}[126,127]$. Similar results have been obtained in studies of children [128]. BAKKE et al. [129] found that subjects with a primary and secondary education had a higher prevalence of spirometric airflow limitation than subjects with a university education with statistically significant age, sex, smoking, and occupation adjusted odds ratios of 5.2 and 1.8 respectively.

The types of symptoms included in many studies do not refer directly to COPD but rather to chronic bronchitis. In general, most of the studies on symptoms have reported results that are consistent with those previously described for lung function [130, 131]. Although the reported studies have used different indices of socioeconomic status including family income, education, residence or occupation, the specific contribution of each of these components is difficult to assess. In a cross-sectional study carried out in Brazil, MENEZES et al. [132] found that poor schooling, poor 
housing and family income were independently associated to chronic bronchitis.

The possibility that the socioeconomic status in early life could be a relevant risk factor of obstructive lung disease was suggested by the results of a longitudinal analysis of the Medical Research Council's national survey of health and development of the 1946 birth cohort [133]. BRITTEN et al. [121] assessed the presence of respiratory symptoms and peak expiratory flow when the subjects included in the study were 36 yrs old and found that in both males and females these respiratory events were independently associated, not only with current indices of poor social circumstances but also with poor home environment at age 2 yrs. In a Danish study the effect of education and income on adult lung function seemed independent of age which could also indicate that the mechanism is related to events taking place before reaching maximally attained lung function in early adulthood [126]. There are many mechanisms that have been considered to be involved in the relationship between socioeconomic status and COPD including intrauterine lung growth, early life exposures, childhood respiratory infections, smoking through childhood to adulthood, occupation, housing and nutrition [125].

The fact that the association between socioeconomic status and COPD is consistent across different types of studies in different populations, has a relevant magnitude and refers to a sizeable segment of the overall population, confers to this relationship a public health relevance that deserves further consideration.

\section{Environmental risk factors in infancy}

One factor that has received close attention is the presence of lower respiratory infection during childhood which has been found to increase the risk of respiratory symptoms [134] and of functional impairment [135]. MANN et al. [136] examining a national birth cohort, found that although bronchitis, bronchiolitis, and pneumonia before the age of 2 yrs were associated with lower peak expiratory flow at the age 36 yrs such association disappeared after adjustment by socioeconomic status and smoking. It is unclear whether constitutional undergrowth of lung function may be a common antecedent for both lower respiratory infections in early life and later development of COPD.

Prenatal smoke exposure has been previously mentioned as a potential risk factor for COPD. The rationale for this hypothesis is based on animal studies showing that foetal lung development is adversely influenced by maternal smoking [137] although it is very difficult to separate the in utero effects from the effects in the postnatal period. Postnatal exposure to smoking has been related to a higher risk of lower respiratory infections and to a decreased FEV1, although the evidence is based on cross-sectional studies or studies including only young people who can not properly inform about the risk of COPD. It has been suggested that passive exposure to smoking may account for a $5 \%$ reduction in the maximal attainable level of FEV1 [138, 139].

\section{Interventions}

The ultimate aim of epidemiology is to identify modifiable determinants of disease occurrence and progression and to contribute in testing the efficacy and effectiveness of interventions on these determinants including the health services. Reducing smoking is, so far, the only well established way for primary prevention of COPD. Although secondary prevention is progressively reaching a major development, in the control of some types of cancer its role in COPD has, so far, received little attention. The use of oxygen therapy and pulmonary rehabilitation do illustrate the role of tertiary prevention in COPD.

The importance of preventing smoking is beyond any doubt one of the most relevant and complex issues in public health and its detailed consideration is beyond the scope of this chapter. However, the prediction of future trends on COPD due to the failure of large-scale prevention of smoking do deserve some attention here. In the frame of the Global Burden of Disease Study MurRAY and LOPEZ [140] have provided mortality projections for the leading causes of death including COPD and shown that, assuming the current trends in smoking the mortality by COPD will see a sharp increase to became the third cause of death in the world by the year 2020. This alarming prediction will be the result of the spread of smoking consumption which has occurred among females in the industrialized countries and that is occurring in the developing world [141, 142]. An example of a recent response to the magnitude of the smoking problem are the guidelines for smoking cessation commissioned by the Health Education Authority in England strongly arguing for a multilevel approach within the National Health Service [132].

The rationale for secondary prevention of COPD is based on the evidence that after smoking cessation the rate of decline of FEV1 becomes slower [16] and parallels the one of nonsmokers, thus reducing the risk of developing COPD. The fact that COPD can be diagnosed at an early stage and that those with diminished lung function may have an important stimuli to either quit smoking or to participate in smoking cessation programmes are arguments in favour of early detection. A prominent study in this field was the Lung Health Study which assessed whether an intervention including smoking cessation and use of inhaled bronchodilator in smokers 35-60 yrs with mild COPD could slow the rate of decline of FEV1 [143]. The smoking intervention consisted in a 12-session smoking cessation programme combining behaviour modification and nicotine gum, followed by a 5-yr maintenance programme to minimize relapse. The results did show that the smoking cessation intervention resulted in a relevant reduction of the decline in FEV1 whereas the impact of the bronchodilator was smaller and reversed after the drug was discontinued [143]. The existence of an effective early treatment may also be a justification for secondary prevention. Several randomized-controlled trials of inhaled steroids therapy in the early stage of COPD have been recently conducted. Although no effect of inhaled corticosteroids on FEV1 decline has been documented this class of drugs may have a role in 
reducing exacerbations in moderate-to-severe COPD [144].

When COPD is already established, medical diagnosis and appropriate treatment are the only alternatives to slow progression, reduce disability and increase life-expectancy. However, the assessment of the final benefit of medical interventions is a complex issue that involves intricate assessments of efficacy, effectiveness and efficiency. Randomized-controlled trials are the gold standard for this type of assessments and the importance of its use in clinical research can not be overemphasized. The only randomized-control trial in support of the influenza vaccination in COPD was provided by a study of general older population with no particular selection of COPD subjects [145]. Although the study did show a statistically significant reduction in the rate of hospital admission for all chronic respiratory causes, it was not possible to estimate the specific effectiveness for COPD patients. In order to assess the influence of influenza vaccination in the course of COPD several observational studies have been reported. HAK et al. [146] carried out a prospective cohort study of 1,696 patients with chronic lung disease including both asthma and COPD and found that in vaccinated $\geqslant 65 \mathrm{yr}$ olds the occurrence of any complication was reduced by $50 \% \quad(95 \% \mathrm{CI}$ : 17-70\%). NicHOL et al. [147] performed a retrospective seasonal cohort study of 1,898 persons $\geqslant 65$ yrs with a diagnosis of COPD and found that influenza vaccination was associated with a lower risk of both hospital admission for pneumonia and influenza (adjusted risk ratio, 0.48 (95\% CI, 0.20-0.82) and death (adjusted risk ratio $0.30(95 \% \mathrm{CI}, 0.21-0.43))$. These studies, although based on uncontrolled interventions, do offer useful information that supports the effectiveness of influenza vaccination in COPD and its recommendation in the current guidelines.

Systematic reviews and meta-analysis have recently emerged as an appropriate approach for summarizing the results of a series of observational or experimental studies on the same topic. The application of metaanalysis to the assessment of an intervention in chronic obstructive pulmonary disease is well illustrated by two studies conducted in chronic obstructive pulmonary disease patients to evaluate pulmonary rehabilitation [148] and respiratory muscle training [149]. Whereas the former did show that participation in general rehabilitation programmes was effective for improving quality of life in chronic obstructive pulmonary disease patients [148] and extended the evidence provided by smaller trials, the latter did not show any relevant benefit for people with chronic obstructive pulmonary disease who followed respiratory muscle training alone [149].

\section{References}

1. Siafakas NM, Vermeire P, Pride NB, et al. Optimal assessment and management of chronic obstructive pulmonary disease (COPD). Eur Respir J 1995; 8: $1398-1420$.

2. ATS Statement. Standards for the Diagnosis and Care of Patients with Chronic Obstructive Pulmonary
Disease. Am J Respir Crit Care Med 1995; 152: S78-S119.

3. Burrows B, Bloom JW, Traver GA, Cline MG. The course and prognosis of different forms of chronic airways obstruction in a sample from the general population. N Engl J Med 1987; 317: 1309-1314.

4. Higgins MW, Thom T. Incidence, prevalence and mortality: intra- and intercountry differences. In: Hensley MJ, Saunders NA, eds. Clinical Epidemiology of Chronic Obstructive Pulmonary Disease. New York, Mercel Dekker Inc., 1989; pp. 23-42.

5. Bang KM. Prevalence of chronic obstructive pulmonary disease in blacks. J Nat Med Assoc 1993; 85: $51-55$.

6. Strachan D. Epidemiology: A British Perspective. In: Calverley P, Pride N, eds. Chronic Obstructive Pulmonary Disease. London, Chapman \& Hall, 1995; pp. 47-67.

7. Cox BD. Blood pressure and respiratory function. In: The health and lifestyle survey. Preliminary report of a nationwide survey of the physical and mental health, attitudes and lifestyle of a random sample of 9003 British adults. London, Health Promotion Research Trust, 1987: pp. 17-33.

8. Sobradillo V, Miravitlles M, Jimenez CA, et al. Epidemiological study of chronic obstructive pulmonary disease in Spain (IBERPOC): prevalence of chronic respiratory symptoms and airflow limitation. Arch Bronconeumol 1999; 35: 159-166.

9. Lange $\mathrm{P}$, Groth $\mathrm{S}$, Nyboe J, et al. Chronic obstructive lung disease in Copenhagen: cross-sectional epidemiological aspects. J Inter Med 1989; 226: 25-32.

10. Bakke PS, Baste V, Hanoa R, et al. Prevalence of obstructive lung disease in a general population: relation to occupational title and exposure to some airborne agents. Thorax 1991; 46: 863-870.

11. Kunzli N, Ackermann-Liebrich U, Brandli O, Tschopp JM, Schindler C, Leuenberger P. Clinically "small" effects of air pollution on FVC have a large public health impact. Swiss Study on Air Pollution and Lung Disease in Adults (SAPALDIA) - team. Eur Respir J 2000; 15: 131-136.

12. Thom TJ. International comparisons in COPD mortality. Am Rev Respir Dis 1989; 140: s27-s34.

13. Mannino DM, Brown C, Giovino GA. Obstructive lung disease deaths in the United States from 1979 through 1993. An analysis using multiple-cause mortality data. Am J Respir Crit Care Med 1997; 156: 814-818.

14. Crokett AJ, Cranston JM, Moss JR, Alpers JH. Trends in chronic obstructive pulmonary disease mortality in Australia. Med J Aust 1994; 161: 600-603.

15. Murray CJ, Lopez AD. Evidence-based health policylessons from the Global Burden of Disease Study. Science 1996; 274: 740-743.

16. Fletcher $\mathrm{CM}$, Peto R, Tinker CM, Spizer FE. The Natural History of Chronic Bronchitis and Emphysema. Oxford, Oxford University Press, 1976.

17. Burrows B, Knudson RJ, Camilli AE, Lyle SK, Lebowitz MD. The "horse-racing effect" and predicting decline in forced expiratory volume in one second from screening spirometry. Am Rev Respir Dis 1987; 135: 788-793.

18. Pride NB, Burrows B. Development of impaired lung function: natural history and risk factors. In: Calverley $\mathrm{P}$, Pride N, eds. Chronic Obstructive Pulmonary Disease. London, Chapman \& Hall, 1995; pp. 69-19. 
19. Rijcken B, Britton J. Epidemiology of chronic obstructive pulmonary disease. Eur Respir Mon 1998; 7: 41-73.

20. Kerstjens HAM, Rijcken B, Schouten JP, Postma DS. Decline of FEV1 by age and smoking status: facts, figures, and fallacies. Thorax 1997; 52: 820-827.

21. Clément J, Van de Woestjne KP. Rapidly decreasing forced expiratory volume in one second or vital capacity and development of chronic airway obstruction. Am Rev Respir Dis 1982; 125: 553-558.

22. Higgins MW, Keller JB, Becker M, et al. An index of risk for obstructive airways disease. Am Rev Respir Dis 1982; 125: 144-151.

23. Medical Research Council. Value of chemoprophylaxis for chronic bronchitis. BMJ 1966; 1: 1317-1322.

24. Annesi I, Kauffman F. Is respiratory mucus hypersecretion really an innocent disorder? A 22-year mortality survey of 1,061 working men. Am Rev Respir Dis 1986; 134: 688-693.

25. Vestbo J, Prescott E, Lange P. Association of chronic mucus hypersecretion with FEV1 decline and chronic obstructive pulmonary disease morbidity. Copenhagen City Heart Study Group. Am J Respir Crit Care Med 1996; 153: 1530-1535.

26. Fletcher CM, Peto R. The natural history of chronic airflow limitation. BMJ 1977; i: 1645-1648.

27. Wolkove N, Dajczman E, Ccolacone A, Kreisman H. The relationship between pulmonary function and dyspnea in obstructive lung disease. Chest 1989; 96: 1247-1251.

28. Jones P, Quirk FH, Baveystock CM, Littlejohns P. A self-complete measure of health status for chronic airflow limitation. The St. George's Respiratory Questionnaire. Am Rev Respir Dis 1992; 145: 1321-1327.

29. Ferrer M, Alonso J, Morera J, et al. Chronic obstructive pulmonary diesase stage and healthrelated quality of life. Ann Int Med 1997; 1072-1079.

30. Burge PS, Calverley PM, Jones PW, Spencer S, Anderson JA, Maslen TK. Randomised, double blind, placebo controlled study of fluticasone propionate in patients with moderate to severe chronic obstructive pulmonary disease: the ISOLDE trial. BMJ 2000; 320: 1297-1303.

31. Spencer S, Calverley PMA, Burge PS, Jones PW, on behalf of the ISOLDE Study Group. Health status deterioration in patients with chronic obstructive pulmonary disease. Am $\mathrm{J}$ Respir Crit Care Med 2001; 163: 122-128.

32. Osman LM, Godden DJ, Friend JAR, Legge JS, Douglas JG. Quality of life and hospital-readmission in patients with chronic obstructive pulmonary disease. Thorax 1997; 52: 67-71.

33. Anthonisen NR, Manfreda J, Warren CP, Hershfield ES, Harding GK, Nelson NA. Antibiotic therapy in exacerbations of chronic obstructive pulmonary disease. Ann Intern Med 1987; 106: 196-204.

34. Seemungal TA, Donaldson GC, Paul EA, Bestall JC, Jeffries DJ, Wedzicha JA. Effect of exacerbation on quality of life in patients with chronic obstructive pulmonary disease. Am J Respir Crit Care Med 1998; 157: 1418-1422.

35. Seneff MG, Wagner DP, Wagner RP, Zimmerman JE, Kanus WA. Hospital and 1-year survival of patients admitted to intensive care units with acute exacerbation of chronic obstructive pulmonary disease. JAMA 1995; 274: 1852-1857.
36. Connors AF Jr, Dawson NV, Thomas C, et al. Outcomes following acute exacerbation of severe chronic obstructive lung disease. Am J Respir Crit Care Med 1996; 154: 959-967.

37. Prescott E, Lange P, Vestbo J. Chronic mucus hypersecretion in COPD and death from pulmonary infection. Eur Respir J 1995; 8: 1333-1338.

38. Menotti A, Blackburn H, Seccareccia F, et al. The relation of chronic diseases to all-cause mortality risk The Seven Countries Study. Ann Med 1997; 29: 135-141.

39. Anthonisen NR, Wright EC, Hodking JE. Prognosis in chronic obstructive pulmonary disease. Am Rev Respir Dis 1986; 133: 14-20.

40. Vestbo J, Prescott E, Lange P, Schnohr P, Jensen G. Vital prognosis after hospitalization for COPD. A study of a random population sample. Respir Med 1998; 92: 772-776.

41. Barter C, Campbell AH. Relationship of constitutional factors and smoking to decrease in 1-second forced expiratory volume. Am Rev Respir Dis 1976; 113: 305-314.

42. Hansen EF, Phanareth K, Laursen LC, Kok-Jensen A, Dirksen A. Reversible and irreversible airflow obstruction as predictor of overall mortality in asthma and chronic obstructive pulmonary disease. $\mathrm{Am}$ J Respir Crit Care Med 1999; 159: 1267-1271.

43. France AJ, Prescott E, Biernacki W. Does right ventricular function predict survival in patients with chronic obstructive pulmonary disease? Thorax 1988; 43: 621-626.

44. Zielinski J, MacNee W, Wedzicha J, et al. Causes of death in patients with COPD and chronic respiratory failure. Monaldi Arch Chest Dis 1997; 52: 43-47.

45. Incalzi RA, Fuso L, De Rosa M, et al. Co-morbidity contributes to predict mortality of patients with chronic obstructive pulmonary disease. Eur Respir $J$ 1997; 10: 2794-2800.

46. Ebi-Kryston KL. Respiratory symptoms and pulmonary function as predictors of 10-year mortality from respiratory disease, cardiovascular disease and all causes in the Witheall study. J Clin Epidemiol 1988; 41: 251-260.

47. Krzyzanowski M, Wysocki M. The relation of thirteen-year mortality to ventilatory impairment and other respiratory symptoms. Int $J$ Epidemiol 1986; 15: 56-64.

48. Kanner RS, Renzetti AD Jr, Klauber MR, et al. Variables associated with changes in spirometry in patients with obstructive lung diseases. $\mathrm{Am} \mathrm{J} \mathrm{Med}$ 1979; 67: 44-50.

49. Lange P, Nyboe J, Appleyard M, Jensen C, Schnohr $P$. The relation of ventilatory impairment and of chronic mucus hypersecretion to mortality from obstructive lung disease and from all causes. Thorax 1990; 45: 579-585.

50. Vilkman S, Keistinen T, Tuuponen T, Kivela SL. Survival and cause of death among elderly chronic obstructive pulmonary disease patients after first admission to hospital. Respiration 1997; 64: 281-284.

51. Sunyer J, Anto JM, McFarlane D, et al. Sex differences in mortality of people who visited emergency rooms for asthma and chronic obstructive disease. Am J Respir Crit Care Med 1998; 158: 851-856.

52. Logan WPD. Mortality in the London fog incident. Lancet 1953; 1: 336-338. 
53. Lawther PF, Waller RE, Henderson M. Air pollution and exacerbation of bronchitis. Thorax 1970; 25: 525-539.

54. Carnow BW, Lepper MH, Shekelle RB, et al. Chicago air pollution study; $\mathrm{SO}_{2}$ levels and acute illness in patients with chronic bronchopulmonary disease. Arch Environ Health 1969; 18: 768-776.

55. Aubry F, Gibbs GW, Beckake MR. Air pollution and health in three urban communities. Arch Environ Health 1979; 34: 360-367.

56. Bouhuys A, Beck GJ, Schoenberg JB. Do present levels of air pollution outdoors affect respiratory health? Nature 1978; 276: 466-471.

57. Schwartz J, Dockery DW. Increased mortality in Philadelphia associated with daily air pollution concentrations. Am Rev Respir Dis 1992; 145: 600-604.

58. Katsouyanni K, Touloumi G, Spix C, et al. Shortterm effects of ambient sulphur dioxide and particulate matter on mortality in 12 European cities: results from the APHEA project. BMJ 1997; 314: 1658-1663.

59. Anderson HR, Spix C, Medina S, et al. Air pollution and daily admissions for chronic obstructive pulmonary disease in 6 European cities: results from the APHEA project. Eur Respir J 1997; 10: 1064-1071.

60. Schwartz J. Air pollution and hospital admissions for the elderly in Birmingham, Alabama. Am J Epidemiol 1994; 139: 589-598.

61. Schwartz J. Air pollution and hospital admissions for the elderly in Detroit, Michigan. Am J Respir Crit Care Med 1994; 150: 648-655.

62. Schwartz J. PM10, ozone, and hospital admissions for the elderly in Minneapolis-St Paul, Minnesota. Arch Environ Health 1994; 49: 366-374.

63. Schwartz J. Air pollution and hospital admissions for respiratory disease. Epidemiology 1996; 7: 20-28.

64. Morgan G, Corbett S, Wlodarczyk J. Air pollution and hospital admissions in Sydney, Australia, 1990 to 1994. Am J Public Health 1998; 88: 1759-1760.

65. Sunyer J, Schwartz J, Tobías A, MacFarlane D, Garcia-Aymerich J, Antó JM. Patients with chronic obstructive pulmonary disease are at increased risk of death associated with urban particle air pollution: a case-crossover analysis. Am J Epidemiol 2000; 151: $50-56$.

66. Samet JM, Dominici F, Curriero F, Coursac I, Zeger SL. Fine particulate air pollution and mortality in 20 U.S. cities, 1987-1994. N England J Med 2000; 343: 1742-1749.

67. Schwartz J. Harvesting and long term exposure effects in the relation between air pollution and mortality. Am J Epidemiol 2000; 151: 440-448.

68. Sandford AJ, Weir TD, Paré PD. Genetic risk factors for chronic obstructive pulmonary disease. Eur Respir $J$ 1997; 10: 1380-1391.

69. Tarjan E, Magyar P, Vaczi Z, Vaszar L. Longitudinal lung function study in heterozygous PiMZ phenotype subjects. Eur Respir J 1994; 7: 2199-2204.

70. Seersholm N, Wilcke JTR, Kok-Jensen A, Dirksen A. Risk of hospital admission for obstructive pulmonary disease in alphal-antitrypsin heterozygotes of phenotype PiMZ. Am J Respir Crit Care Med 2000; 161: 81-84.

71. Siafakas NM. Microsatellite DNA instability in COPD. Chest 1999; 116: 47-51.

72. Ishii T. Glutathione S-transferase P1 (GSTP1) polymorphism in patients with chronic obstructive pulmonary disease. Thorax 1999; 54: 693-696.

73. Gold DR, Wang X, Wypij D, Spizer FE, Ware JH, Dockery DW. Effects of cigarette smoking on the pulmonary function in adolescent boys and girls. $N$ Engl J Med 1996; 335: 931-937.

74. Schwartz J, Katz SA, Fegley RW, Tockman MS. Sex and race differences in the development of lung function. Am Rev Respir Dis 1988; 138: 1415-1421.

75. Prescott E, Osler M, Vestbo J. Importance of detailed adjustment for smoking when comparing morbidity and mortality in men and women in a Danish population study. Eur J Publ Health 1998; 8: 166-169.

76. Prescott E, Bjerg AM, Andersen PK, Lange P, Vestbo J. Gender difference in smoking effects on lung function and risk for hospitalization for COPD. Results from a Danish longitudinal population study. Eur Respir J 1997; 10: 822-827.

77. Silverman E. Gender-related differences in severe, early-onset COPD. Am J Resp Crit Care Med 2000; 162: 2152-2158.

78. Paoletti P, Carrozzi L, Viegi G, et al. Distribution of bronchial responsiveness in a general population: effect of sex, age, smoking, and level of pulmonary function. Am J Respir Crit Care Med 1995; 151: 1770-1777.

79. Scott TW, Sparrow D, eds, Airways Responsiveness and Atopy in the Development of Chronic Lung Disease. New York, Raven Press, 1989.

80. Xu X, Rijcken B, Schouten JP, Weiss ST. Airways responsiveness and development and remission of chronic respiratory symptoms in adults. Lancet 1997; 350: 1431-1434.

81. Hospers J, Postma DS, Rijcken B, Weiss ST, Schouten JP. Histamine airway hyper-responsiveness and mortality from chronic obstructive pulmonary disease: a cohort study. Lancet 2000; 356: 1313-1317.

82. Peat JK, Woolcock AJ, Cullen K. Rate of decline of lung function in subjects with asthma. Eur J Respir Dis 1987; 70: 171-179.

83. Lange P, Parner J, Vestbo J, Jensen G, Schnohr P. A 15-year follow-up of ventilatory function in adults with asthma. N Engl J Med 1998; 339: 1194-1200.

84. Berhane K. Sex-specific effects of asthma on pulmonary function in children. Am J Respir Crit Care Med 2000; 162: 1723-1730.

85. Lange $\mathrm{P}$, Ulrik CS, Vestbo $\mathbf{J}$ and for The Copenhagen City Heart Study Group. Mortality in adults with selfreported bronchial asthma. A study of the general population. Lancet 1996; 347: 1285-1289.

86. O'Connor GT, Sparrow D, Weiss ST. A prospective longitudinal study of methacholine airway responsiveness as a predictor of pulmonary-function decline: the Normative Aging Study. Am J Respir Crit Care Med 1995; 152: 87-92.

87. Tashkin PD, Detels R, Simmons M, et al. The UCLA population studies of chronic obstructive respiratory disease: XI. Impact of air pollution and smoking on annual change in forced expiratory volume in one second. Am J Respir Crit Care Med 1994; 149: 1209-1217.

88. United States Department of Health and Human Services, Public Health Service. The health benefits of smoking cessation. A report of the Surgeon General. US Government Printing Office, Washington DC, 1990.

89. Cook DG, Strachan DP. Summary of parental 
smoking on the effects of parental smoking on the respiratory health of children and implications for research. Thorax 1999; 54: 357-366.

90. Holland WW, Reid DD. The urban factor in chronic bronchitis. Lancet 1965; i: 445-446.

91. Van der Lende R, Kok TJ, Peset Reig R, Quanjer PhT, Schouten JO, Orie NGM. Decreases in FVC and FEV1 with time: indicators for effects of smoking and air pollution. Bull Eur Physiopathol Respir 1981; 17: 775-792.

92. Detels R, Tashkin DP, Sayre JW, et al. The UCLA population studies of CORD: X. A cohort study of changes in respiratory function associated with chronic exposure to $\mathrm{SO}_{\mathrm{X}}, \mathrm{NO}_{\mathrm{X}}$, and hydrocarbons. Am J Public Health 1991; 81: 350-359.

93. Ackermann-Liebrich U, Leuenberger P, Schwartz J, et al. SAPALDIA team. Lung function and long term exposure to air pollutants in Switzerland. Am J Respir Crit Care Med 1997; 155: 122-129.

94. Schindler C, Ackermann-Liebrich U, Leuenberger P, et al. SAPALDIA team. Associations between lung function and estimated average exposure to $\mathrm{NO}_{2}$ in eight areas of Switzerland. Epidemiology 1998; 9: 405-411.

95. Abbey DE, Burchette RJ, Knutsen SF, McDonnell WF, Lebowitz MD, Enright PL. Long-term particulate and other air pollutants and lung function in nonsmokers. Am J Respir Crit Care Med 1998; 158: 289-298.

96. Stern BR, Raizenne ME, Burnett RT, Jones L, Kearney J, Franklin CA. Air pollution and childhood respiratory health: exposure to sulfate and ozone in 10 Canadian rural communities. Environ Res 1994; 66: 125-142.

97. Raizenne M, Neas LM, Damokosh AI, et al. Health effects of acid aerosols on North American children: pulmonary function. Environ Health Perspect 1996; 104: 506-514.

98. Peters JM, Avol E, Gauderman J, et al. A study of twelve southern California communities with different levels and types of air pollution. Effects on pulmonary function. Am J Respir Crit Care Med 1999; 159: 768-775.

99. Jedrychowski W, Flak E, Mroz E. The adverse effect of low levels of ambient air pollutants on lung function growth in preadolescent children. Env Health Perspect 1999; 107: 669-674.

100. Gauderman WJ, Ms Connell R, Gilliand F, et al. Association between air pollution and lung function growth in southern California children. Am J Respir Crit Care Med 2000; 162: 1383-1390.

101. Frisher T, Studnicka M, Gartner Ch, et al. Lung function growth and ambient ozone. A three year population study in school children. Am J Respir Crit Care Med 1999; 160: 390-396.

102. Fairbairn AS, Reid DD. Air pollution and other local factors in respiratory disease. Brit J Prev Soc Med 1958; 12: 94-103.

103. Lambert PM, Reid DD. Smoking, air pollution and bronchitis in Britain. Lancet 1970; 1: 853-857.

104. Ferris BG, Higgins TT, Higgins MW, et al. Chronic nonspecific respiratory disease, Bertin NH. 1961-1967. A cross sectional study. Am Rev Resp Dis 1971; 104: 232-244.

105. Love G, Shu Ping Lan, Smy C, et al. The incidence and severely of acute respiratory illness in families exposed to different levels of air pollution, New York
Metropolitan Area, 1971-1972. Arch Environ Health 1981; 36: 66-74.

106. Burrows B, Kellogg ALL, Buskey S. Relationship of symptoms of chronic bronchitis and emphysema to matter and air pollution. Arch Environ Health 1968; 16: 406-413.

107. Sawiki F. Chronic non-specific respiratory diseases in the city of Cracow. Epidemiol Rev 1972; 26: 229-250.

108. Euler G, Abbey DE, Magie AR, Hodgkin J. Chronic obstructive pulmonary disease symptom effects of long-term cumulative exposure to ambient levels of total suspended particulates and sulfur dioxide in California Seventh-day Adventist residents. Arch Environ Health 1987; 42: 213-222.

109. Zemp E, Elsasser S, Schindler C, et al. SAPALDIA team. Long-term ambient air pollution and respiratory symptoms in adults (SAPALDIA study). Am J Respir Crit Care Med 1999; 159: 1257-1266.

110. Dockery DW, Pope CA, Xu X, et al. An association between air pollution and mortality in six US cities. $N$ Eng J Med 1993; 32: 1753-1759.

111. Pope CA, Thun MJ, Namboodiri MM, et al. Particulate air pollution as a predictor of mortality in a prospective study of US adults. Am J Respir Crit Care Med 1995; 151: 669-674.

112. Abbey DE, Mills PK, Petersen FF, Beeson WL. Longterm ambient concentrations of total suspended particulates and oxidants as related to incidence of chronic disease in California preadolescent children. Am Rev Respir Dis 1986; 133: 834-852.

113. Abbey DE, Nishino N, McDonell WF, et al. Longterm inhalable particles and other air pollutants related to mortality in non-smokers. Am $J$ Respir Crit Care Med 1999; 159: 372-382.

114. Hendrick DJ. Occupation and chronic obstructive pulmonary disease. Thorax 1996; 51: 947-955.

115. Heederik D, Kromhout H, Burema J, Biersteker K, Kromhout D. Occupational exposure and 25-year incidence of nonspecific lung disease: the Zutphen Study. Int J Epidemiol 1990; 19: 945-952.

116. Post WK, Heederik D, Kromhout H, Kromhout D. Occupational exposures estimated by a population specific job exposure matrix and 25 year incidence rate of chronic nonspecific lung disease (CNSLD): the Zutphen Study. Eur Respir J 1994; 7: 1048-1055.

117. Oxman OD, Guyatt GH. Guidelines for reading literature reviews. Can Med Assoc J 1988; 138: 697-703.

118. Oxman AD, Muir DCF, Shannon HS, Stock SR, Hnizdo E, Lange HJ. Occupational dust exposure and chronic obstructive lung disease. Am Rev Respir Dis 1993; 148: 38-48.

119. Strachan DP, Cox BD, Erzinclioglu SW, Walters DE, Whichelow MJ. Ventilatory function and winter fresh fruit consumption in a random sample of British adults. Thorax 1991; 46: 624-629.

120. Schwartz J, Weiss ST. Dietary factors and their relation to respiratory symptoms. Am J Epidemiol 1990; 132: 67-76.

121. Britton J, Pavord I, Richards K, et al. Dietary magnesium, lung function, wheezing, and airway hyperreactivity in a random adult population sample. Lancet 1994; 344: 357-362.

122. Shahar E, Folsom AR, Melnick SL, et al. Dietary n-3 polyunsaturated fatty acids and smoking-related chronic obstructive pulmonary disease. Athero- 
sclerosis risk in Communities Study Investigators. N Engl J Med 1994; 331: 228-233.

123. Miedema I, Feskens EJ, Heederik D, Kromhout D. Dietary determinants of long-term incidence of chronic nonspecific lung diseases. The Zutphen Study. Am J Epidemiol 1993; 138: 37-45.

124. Swartz J. Role of polyunsaturated fatty acids in lung disease. Am J Clin Nutrition 2000; 71: Suppl. 1, 393S-396S.

125. Prestcott E. Socioeconomic status and chronic obstructive pulmonary disease. Thorax 1999; 54: 737-741.

126. Prescott E, Lange P, Vestbo $\mathbf{J}$ and the Copenhagen City Heart Study Group. Socioeconomic status, lung function, and admission to hospital for COPD. Results from the Copenhagen City Heart Study. Eur Respir J 1999; 13: 1109-1114.

127. Krzyzanowski M, Jedrychowski W, Wysocki M. Factors associated with the change in ventilatory function and the development of chronic obstructive pulmonary disease in a 13-year follow-up of the Cracow study. Am Rev Respir Dis 1986; 134: 1011-1019.

128. Demissie K. Socioeconomic status and lung function among primary school children in Canada. Am J Respir Crit Care Med 1996; 153: 719-723.

129. Bakke PS, Hanoa R, Gulsvik A. Educational level and obstructive lung disease given smoking habits and occupational airborne exposure: a Norwegian community study. Am J Epidemiol 1995; 141: 1080-1088.

130. Lebowitz MD. The relationship of socio-environmental factors to the prevalence of obstructive lung disease and other chronic conditions. J Chronic Dis 1977; 30: 599-611.

131. Burr M. Why is chest disease so common in South Wales? Smoking, social class, and lung function: a survey of elderly men in two areas. $J$ Epidemiol Community Health 1987; 41: 140-144.

132. Menezes AMB, Victora CG, Rigatto M. Prevalence and risk factors for chronic bronchitis in Pelotas, Brazil: a population-based study. Thorax 1994; 49: 1217-1221.

133. Britten N, Daves JMC, Colley JRT. Early respiratory experience and subsequent cough and peak expiratory flow rate in 36 year old men and women. BMJ 1987; 294: 1317-1320.

134. Paoletti P, Prediletto R, Carrozzi L, et al. Effects of childhood and adolescence-adulthood respiratory infections in a general population. Eur Respir $J$ 1989; 2: 428-436.

135. Burrows B, Knudson RJ, Cline MG, Lebowitz MD. A reexamination of risk factors for ventilatory impairment. Am Rev Respir Dis 1988; 138: 829-836.

136. Mann SL, Wadsworth MEJ, Colley JRT. Accumulation of factors influencing respiratory illness in members of a national birth cohort and their offspring. J Epidemiol Community Health 1992; 46: 286-292.

137. Collins $\mathrm{MH}$, Moessinger AC, Kleinerman $\mathrm{J}$, et al. Fetal lung hypoplasia associated with maternal smoking: a morphometric analysis. Pediatr Res 1985; 19: 408-412.

138. Hanrahan JP, Tigwer I, Segal MR. The effects of maternal smoking during pregnancy on early infant lung function. Am Rev Respir Dis 1992; 145: $1129-1135$.

139. Davis R. The epidemiology of cigarette smoking and its impact on chronic obstructive pulmonary disease. Am Rev Respir Dis 1989; 140: s82-s84.

140. Murray CJ, Lopez AD. Alternative projections of mortality and disability by cause 1990-2020: Global Burden of Disease Study. Lancet 1997; 349: 1498-1504.

141. Chen ZM, Xu Z, Collins R, Li WX, Peto R. Early health effects of the emerging tobacco epidemic in China. A 16-year prospective study. JAMA 1997; 278: $1531-1532$.

142. Liu BQ, Peto R, Chen ZM, et al. Emerging tobacco hazards in China: 1. Retrospective mortality study of one million deaths. BMJ 1998; 317: 1411-1422.

143. Anthonisen NR, Connett JE, Kiley JP, et al. Effects of smoking intervention and the use of an inhaled anticholinergic bronchodilator on the rate of decline of FEV1. The Lung Health Study. JAMA 1994; 272 : 1497-1505.

144. Mapp CE. Inhaled glucocorticoids in chronic obstructive pulmonary disease. New Engl J Med 2000; 343: 1960-1961.

145. Govaert TM, Thijs CT, Masurel N, Sprenger MJ, Dinant GJ, Knottnerus JA. The efficacy of influenza vaccination in elderly individuals. A randomized double-blind placebo-controlled trial. JAMA 1994; 272: $1661-1665$

146. Hak E, van Essen G, Buskens E, Stalman W, de Melker RA. Is immunising all patients with chronic lung disease in the community against influenza cost effective? Evidence from a general practice based clinical prospective cohort study in Utrecht, The Netherlands. J Epidemiol Community Health 1998; 52: $120-125$.

147. Nichol KL, Baken L, Nelson A. Relation between influenza vaccination and outpatients visits, hospitalization, and mortality in elderly persons with chronic lung disease. Ann Intern Med 1999; 130: 397-403.

148. Lacasse Y, Wong E, Guyatt GH, King D, Cook DJ, Goldstein RS. Meta-analysis of respiratory rehabilitation in chronic obstructive pulmonary disease. Lancet 1996; 348: 1115-1119.

149. Smith K, Hook D, Guyatt GH, Madhavan J, Oxman AD. Respiratory muscle training in chronic airflow limitation: meta-analysis. Am Rev Respir Dis 1992; 145: 533-539. 